\title{
Patterns of lung cancer mortality in 23 countries: Application of the Age-Period-Cohort model Yung-Po Liaw*1, Yi-Chia Huang ${ }^{2}$ and Guang-Wen Lien ${ }^{1}$
}

\author{
Address: ${ }^{1}$ Department of Public Health, Chung Shan Medical University, Taichung, 402, Taiwan and ${ }^{2}$ School of Nutrition, Chung Shan Medical \\ University, Taichung, 402, Taiwan \\ Email: Yung-Po Liaw* - Liawyp@csmu.edu.tw; Yi-Chia Huang - ych@csmu.edu.tw; Guang-Wen Lien - s80208@csmu.edu.tw \\ * Corresponding author
}

Published: 05 March 2005

BMC Public Health 2005, 5:22 doi:10.1 I86/147I-2458-5-22
Received: 09 April 2004

Accepted: 05 March 2005

This article is available from: http://www.biomedcentral.com/I47I-2458/5/22

(c) 2005 Liaw et al; licensee BioMed Central Ltd.

This is an Open Access article distributed under the terms of the Creative Commons Attribution License (http://creativecommons.org/licenses/by/2.0), which permits unrestricted use, distribution, and reproduction in any medium, provided the original work is properly cited.

\begin{abstract}
Background: Smoking habits do not seem to be the main explanation of the epidemiological characteristics of female lung cancer mortality in Asian countries. However, Asian countries are often excluded from studies of geographical differences in trends for lung cancer mortality. We thus examined lung cancer trends from 197I to 1995 among men and women for 23 countries, including four in Asia.
\end{abstract}

Methods: International and national data were used to analyze lung cancer mortality from 197| to 1995 in both sexes. Age-standardized mortality rates (ASMR) were analyzed in five consecutive five-year periods and for each five-year age group in the age range 30 to 79. The age-period-cohort (APC) model was used to estimate the period effect (adjusted for age and cohort effects) for mortality from lung cancer.

Results: The sex ratio of the ASMR for lung cancer was lower in Asian countries, while the sex ratio of smoking prevalence was higher in Asian countries. The mean values of the sex ratio of the ASMR from lung cancer in Taiwan, Hong Kong, Singapore, and Japan for the five 5-year period were $2.10,2.39,3.07$, and 3.55 , respectively. These values not only remained quite constant over each five-year period, but were also lower than seen in the western countries. The period effect, for lung cancer mortality as derived for the 23 countries from the APC model, could be classified into seven patterns.

Conclusion: Period effects for both men and women in 23 countries, as derived using the APC model, could be classified into seven patterns. Four Asian countries have a relatively low sex ratio in lung cancer mortality and a relatively high sex ratio in smoking prevalence. Factors other than smoking might be important, especially for women in Asian countries.

\section{Background}

Worldwide, over one million people die of lung cancer each year [1]. In the US, lung cancer is the most common cause of cancer deaths in both sexes [2], and mortality rates in women have risen $500 \%$ since 1950 [3]. In the
European Union countries, although age-standardized mortality rates have decreased for most cancer sites, lung cancer mortality rates have significantly risen in women [4]. A rising death rate from lung cancer has also been observed in Taiwan. Between 1971 and 2001, age-stand- 
ardized lung cancer mortality rates per 100000 per year in Taiwan have increased sharply, from 12.66 to 32.93 among men and from 7.83 to 14.94 among women [5]. Today, in Taiwan, lung cancer is the leading cause of cancer death in women and the second leading cause in men [5].

Epidemiological studies have shown that cigarette smoking is the major cause of lung cancer in both sexes [6-8]. However, smoking habits do not seem to be the main explanation of the epidemiological characteristics of female lung cancer mortality in Asian countries [9-13], where the prevalence of smoking is relatively low but lung cancer mortality rates are relatively high. Factors other than smoking habits might contribute to the variability in lung cancer mortality.

Long-term geographical trends in cancer mortality can provide useful information to assist etiological research. However, Asian countries are often excluded from studies of geographical differences in trends in lung cancer mortality. In order to clarify the changing patterns of lung cancer mortality worldwide, we examined lung cancer trends from 1971 to 1995 among men and women for 23 countries including four from Asia - Taiwan, Japan, Singapore, and Hong Kong. In addition, we plotted the pattern of mortality rate in these countries by using the age-periodcohort (APC) model.

\section{Methods}

We used data from the World Health Organization (WHO) and Taiwan to analyze secular trends from 19711995 in lung cancer mortality in both men and women. Mortality data provided by WHO were relatively incomplete in some countries, so we analyzed data from 22 countries and Taiwan. The twenty-two countries - Hong Kong, Singapore, Japan, Portugal, Poland, Italy, Cuba, Spain, Hungary, France, Greece, Finland, United States, England and Wales, Netherlands, Belgium, Canada, Australia, New Zealand, Denmark, Norway and Sweden - are members of WHO. The data for Taiwan came directly from the Office of Statistics, Department of Health in Taiwan. Since rates for the under 30-year age group are often based on few deaths, and rates for the over 80-year group might be affected by competitive death effects, only rates for the age range 30 to 79 were considered, so as to ensure adequate reliability of the estimates. Lung cancer mortality rates between 1971 and 1995 were analyzed in five consecutive five year periods (1971-1975, 1976-1980, 1981-1985, 1986-1990, and 1991-1995) and in five year age groups.

\section{Statistical methods}

Age-standardized mortality rates (ASMR) were calculated using the world population for 1976 as the reference [14].
Percent changes in the ASMR were calculated as $\left[\left(\mathrm{ASMR}_{1991-1995}-\mathrm{ASMR}_{1971-1975}\right) /\left(\mathrm{ASMR}_{1971-1975}\right)\right] \times$ 100.

In order to apply the APC model, the matrix of age-specific death rates was calculated for each 5-year calendar period (from 1971-1975 to 1991-1995) and age group (from 30-34 to 75-79). The effect of period of death in the APC model was evaluated by a log-linear Poisson model with a modified method as described by Osmond and Gardner [15]. Briefly, the estimate of period effect results from minimizing the weighted sum of the Euclidean distances from the three possible two-factor models (age/period; age/cohort; period/cohort). The weights used in the minimization process were based on the goodnessof-fit measures of each two-factor model. In this study, these were taken as the inverse of the deviance statistics. The sum of period effects were constrained to be zero. These "effects" can be interpreted as logarithms of "relative" risks. These relative risks were estimated separately for men and women. A computer program written in the SAS/IML language [16] was developed to perform the above calculations.

\section{Results}

Age-standardized mortality rates from lung cancer per 100 000 population per year in 23 countries for 1971 to 1995 are listed for men in Table 1 and for women in Table 2. Trends in the ASMR varied by sex. From 1971 to 1995, in men, the rates progressively increased in nine countries (Portugal, Hungary, Taiwan, Spain, Poland, Japan, Norway, France and Greece), progressively decreased in two countries (England and Wales and Finland) and increased then declined in the others. In women, rates increased between 1971-1975 and 1991-1995 in 23 countries except for Hong Kong, Cuba, and Spain, with the highest increasing rate observed in the Netherlands (223.46\%).

Table 3 shows the sex ratio (male:female) of the ASMR for lung cancer for five consecutive five- year periods in 23 countries. The sex ratio was greater than one in each fiveyear period, indicating that the ASMR from lung cancer was higher in men than in women. Among the 23 countries, the trend in the sex ratio gradually decreased for the whole period in most countries except for Spain, France, Italy, Poland, Greece, Portugal, Hungary, Cuba and the Asian countries. For example, in 1971-1975, the highest sex mortality ratio was seen in the Netherlands with a sex ratio of 17.95 , the ratio then gradually decreasing to a value of 4.75 by $1991-1995$. The change in the sex ratio of mortality in the Netherlands might be due to the increase and then decrease in male lung cancer mortality and simultaneously to the increase in female lung cancer mortality. On the other hand, the ratio gradually increased in Spain. This might be due to Spain having the 
Table I: Age-standardized mortality rate (per 100000 person years) from lung cancer in males in 23 countries, 197 I-I995

\begin{tabular}{|c|c|c|c|c|c|c|c|}
\hline \multirow[b]{2}{*}{ Country } & \multicolumn{5}{|c|}{ ASMR } & \multirow[b]{2}{*}{$\begin{array}{l}\text { Percent } \\
\text { increase* }\end{array}$} & \multirow[b]{2}{*}{ Rank $^{\$}$} \\
\hline & $197 \mid-1975$ & $1976-1980$ & $1981-1985$ & $1986-1990$ & $1991-1995$ & & \\
\hline Portugal & 31.88 & 40.51 & 45.96 & 54.40 & 59.48 & 86.57 & I \\
\hline Hungary & 97.10 & 116.05 & 138.49 & 161.34 & $180.9 \mid$ & 86.31 & 2 \\
\hline Taiwan & 32.08 & 39.80 & 49.95 & 54.24 & 58.44 & 82.17 & 3 \\
\hline Spain & 56.92 & 68.84 & 80.68 & 93.80 & 101.49 & 78.30 & 4 \\
\hline Poland & 93.91 & 113.65 & 135.11 & 152.23 & 158.34 & 68.60 & 5 \\
\hline Japan & 38.88 & 46.55 & 53.40 & 56.96 & 59.44 & 52.87 & 6 \\
\hline Norway & 45.20 & 53.24 & 62.61 & 65.43 & 67.36 & 49.03 & 7 \\
\hline France & 74.81 & 87.45 & 93.16 & 99.32 & 100.08 & 33.77 & 8 \\
\hline Greece & 79.55 & 93.63 & 99.23 & 103.77 & 105.44 & 32.54 & 9 \\
\hline Italy & 94.59 & 110.47 & 123.02 & 125.63 & 117.10 & 23.80 & 10 \\
\hline Hong Kong & 94.96 & 118.63 & 116.24 & 116.89 & 110.13 & 15.97 & 11 \\
\hline Canada & 96.68 & 108.38 & 116.23 & 118.13 & 107.71 & 11.42 & 12 \\
\hline USA & 109.60 & 117.87 & 121.16 & 120.33 & 115.23 & 5.13 & 13 \\
\hline Denmark & 101.45 & 109.36 & 116.83 & 113.21 & 103.74 & 2.26 & 14 \\
\hline Sweden & 48.34 & 52.24 & 50.10 & 48.56 & 48.21 & -0.27 & 15 \\
\hline Singapore & 92.34 & 114.24 & 115.29 & 102.90 & 91.47 & -0.95 & 16 \\
\hline Belgium & 146.33 & $163.4 \mid$ & 166.59 & 155.70 & | 44.87 & -1.00 & 17 \\
\hline Cuba & 75.86 & 76.35 & 76.59 & 76.16 & 72.90 & -3.90 & 18 \\
\hline Netherlands & 151.10 & 162.14 & 160.49 & 148.73 & 129.40 & -14.36 & 19 \\
\hline Australia & 99.14 & 100.74 & 100.11 & 90.81 & 80.86 & -18.44 & 20 \\
\hline New Zealand & 99.81 & 104.55 & 100.52 & 93.07 & 79.31 & -20.54 & 21 \\
\hline $\begin{array}{l}\text { England and } \\
\text { Wales }\end{array}$ & 159.59 & 152.45 & 136.82 & 120.40 & 101.21 & -36.58 & 22 \\
\hline Finland & 142.74 & $|42.5|$ & 126.97 & 105.58 & 90.20 & -36.81 & 23 \\
\hline
\end{tabular}

*percent increase $(\%)=100 \times\left(\right.$ ASMR $_{1991-1995}-$ ASMR $\left._{1971-1975}\right) /\left(\right.$ ASMR $\left._{1971-1975}\right)$

$\$$ Rank by percent increase

Table 2: Age-standardized mortality rate (per 100000 person years) from lung cancer in females in 23 countries, 197 I-1995

\begin{tabular}{|c|c|c|c|c|c|c|c|}
\hline \multirow[b]{2}{*}{ Country } & \multicolumn{5}{|c|}{ ASMR } & \multirow[b]{2}{*}{$\begin{array}{c}\text { percent } \\
\text { increase* }\end{array}$} & \multirow[b]{2}{*}{ Rank $^{\$}$} \\
\hline & $197 \mid-1975$ & $1976-1980$ & $1981-1985$ & $1986-1990$ & $1991-1995$ & & \\
\hline Netherlands & 8.42 & 11.06 & 15.46 & 20.80 & 27.24 & 223.46 & 1 \\
\hline Norway & 8.86 & 11.02 & $|5.6|$ & 21.21 & 26.42 & 198.24 & 2 \\
\hline Denmark & 21.25 & 29.28 & 40.86 & 49.78 & 58.41 & 174.91 & 3 \\
\hline Canada & 17.94 & 25.44 & 34.93 & 43.53 & 49.13 & 173.81 & 4 \\
\hline USA & 24.96 & 33.85 & 43.41 & 51.50 & 56.51 & 126.46 & 5 \\
\hline Hungary & 16.75 & 19.34 & 22.99 & 29.11 & 36.83 & 119.89 & 6 \\
\hline Sweden & 11.36 & 13.47 & 16.96 & 20.68 & 24.50 & 115.72 & 7 \\
\hline Poland & 11.40 & 13.66 & $|6.4|$ & 19.68 & 22.90 & 100.83 & 8 \\
\hline Australia & $14.9 \mid$ & 19.70 & 23.61 & 26.47 & 28.47 & 90.99 & 9 \\
\hline Belgium & 10.74 & $|2.3|$ & 13.79 & 16.45 & 19.86 & 84.90 & 10 \\
\hline New Zealand & 22.58 & 26.88 & 30.83 & 36.53 & 38.00 & 68.29 & 11 \\
\hline France & 7.07 & 7.44 & 8.42 & 9.97 & 11.89 & 68.19 & 12 \\
\hline Finland & 8.71 & 11.35 & 12.39 & 13.48 & 14.54 & 67.02 & 13 \\
\hline Taiwan & 16.03 & 19.55 & 23.13 & 25.69 & 26.43 & 64.94 & 14 \\
\hline Italy & 10.69 & 12.12 & $|3.5|$ & 15.09 & 16.23 & 51.86 & 15 \\
\hline
\end{tabular}


Table 2: Age-standardized mortality rate (per 100000 person years) from lung cancer in females in 23 countries, 197 I-1995 (Continued)

\begin{tabular}{|c|c|c|c|c|c|c|c|}
\hline $\begin{array}{l}\text { England and } \\
\text { Wales }\end{array}$ & 30.45 & 35.75 & 40.06 & 43.52 & 42.84 & 40.68 & 16 \\
\hline Portugal & 6.74 & 7.14 & 7.97 & 8.56 & 9.43 & 39.97 & 17 \\
\hline Japan & 11.90 & 13.60 & 14.97 & 15.35 & 15.73 & 32.25 & 18 \\
\hline Greece & 12.64 & 13.57 & 13.21 & 13.86 & 14.28 & 12.97 & 19 \\
\hline Singapore & 29.66 & 34.34 & 37.07 & 36.01 & 31.25 & 5.36 & 20 \\
\hline Hong Kong & 44.18 & 48.99 & 48.01 & 48.32 & 43.14 & -2.34 & 21 \\
\hline Cuba & 27.87 & 26.63 & 26.90 & 27.77 & 27.03 & -3.02 & 22 \\
\hline Spain & 8.54 & 7.99 & 7.32 & 7.01 & 7.58 & -11.27 & 23 \\
\hline
\end{tabular}

* percent increase $(\%)=100 \times\left(\right.$ ASMR $\left._{1991-1995}-\mathrm{ASMR}_{1971-1975}\right) /\left(\mathrm{ASMR}_{1971-1975}\right)$

$\$$ Rank by percent increase

Table 3: Sex ratio of the age-standardized mortality rate from lung cancer in 23 countries, 197 I-1995

\begin{tabular}{|c|c|c|c|c|c|c|c|c|}
\hline \multirow[b]{2}{*}{ Country } & \multicolumn{5}{|c|}{ Ratio } & \multirow[b]{2}{*}{ Mean } & \multirow[b]{2}{*}{ Range } & \multirow[b]{2}{*}{ Rank* } \\
\hline & $197 \mid-1975$ & $1976-1980$ & $198 \mid-1985$ & $1986-1990$ & $199 \mid-1995$ & & & \\
\hline Belgium & 13.62 & 13.27 & 12.08 & 9.46 & 7.29 & 11.15 & 6.33 & 1 \\
\hline Netherlands & 17.95 & 14.67 & 10.38 & 7.15 & 4.75 & 10.98 & 13.20 & 2 \\
\hline Finland & 16.40 & 12.56 & 10.25 & 7.83 & 6.20 & 10.65 & 10.20 & 3 \\
\hline Spain & 6.66 & 8.62 & 11.02 & 13.39 & 13.39 & 10.62 & 6.73 & 4 \\
\hline France & 10.58 & 11.76 & 11.06 & 9.97 & 8.42 & 10.36 & 3.34 & 5 \\
\hline Italy & 8.85 & 9.12 & 9.11 & 8.33 & 7.21 & 8.52 & 1.91 & 6 \\
\hline Poland & 8.24 & 8.32 & 8.23 & 7.73 & 6.91 & 7.89 & 1.41 & 7 \\
\hline Greece & 6.30 & 6.90 & 7.51 & 7.49 & 7.39 & 7.12 & 1.21 & 8 \\
\hline Portugal & 4.73 & 5.67 & 5.77 & 6.36 & 6.31 & 5.77 & 1.63 & 9 \\
\hline Hungary & 5.80 & 6.00 & 6.03 & 5.54 & 4.91 & 5.66 & 1.12 & 10 \\
\hline Australia & 6.65 & 5.11 & 4.24 & 3.43 & 2.84 & 4.45 & 3.81 & 11 \\
\hline Norway & 5.10 & 4.83 & 4.01 & 3.09 & 2.55 & 3.92 & 2.55 & 12 \\
\hline $\begin{array}{l}\text { England and } \\
\text { Wales }\end{array}$ & 5.24 & 4.26 & 3.42 & 2.77 & 2.36 & 3.61 & 2.88 & 13 \\
\hline Canada & 5.39 & 4.26 & 3.33 & 2.71 & 2.19 & 3.58 & 3.20 & 14 \\
\hline Japan & 3.27 & 3.42 & 3.57 & 3.71 & 3.78 & 3.55 & 0.51 & 15 \\
\hline New Zealand & 4.42 & 3.89 & 3.26 & 2.55 & 2.09 & 3.24 & 2.33 & 16 \\
\hline Denmark & 4.77 & 3.74 & 2.86 & 2.27 & 1.78 & 3.08 & 2.99 & 17 \\
\hline Sweden & 4.26 & 3.88 & 2.95 & 2.35 & 1.97 & 3.08 & 2.29 & 18 \\
\hline Singapore & 3.11 & 3.33 & 3.11 & 2.86 & 2.93 & 3.07 & 0.47 & 19 \\
\hline USA & 4.39 & 3.48 & 2.79 & 2.34 & 2.04 & 3.01 & 2.35 & 20 \\
\hline Cuba & 2.72 & 2.87 & 2.85 & 2.74 & 2.70 & 2.78 & 0.17 & 21 \\
\hline Hong Kong & 2.15 & 2.42 & 2.42 & 2.42 & 2.55 & 2.39 & 0.40 & 22 \\
\hline Taiwan & 2.00 & 2.04 & 2.16 & 2.11 & 2.21 & 2.10 & 0.21 & 23 \\
\hline
\end{tabular}

*Rank by mean

the fourth highest increase in male lung cancer mortality accompanied by a progressive decrease in female lung cancer mortality from 1971-1975 through 1986-1990, followed by a slight increase.

The mean values of the sex ratio of the ASMR from lung cancer in Taiwan, Hong Kong, Cuba, Singapore, and Japan were 2.10, 2.39, 2.78, 3.07, and 3.55, respectively, with a range of 0.17 to 0.51 over the five-year periods. These values were not only relatively constant over time, but were also lower than seen in the western countries. For example, the lowest sex ratio of 2.10 was seen in Taiwan, with the sex ratio remaining a relatively constant value over the entire period.

Only age is adjusted when the ASMR is calculated. However, both age and cohort effect are adjusted in the APC model. The period effects for males and females from the APC model applied to the data from the 23 countries could be classified into seven patterns: 1) an increasing 

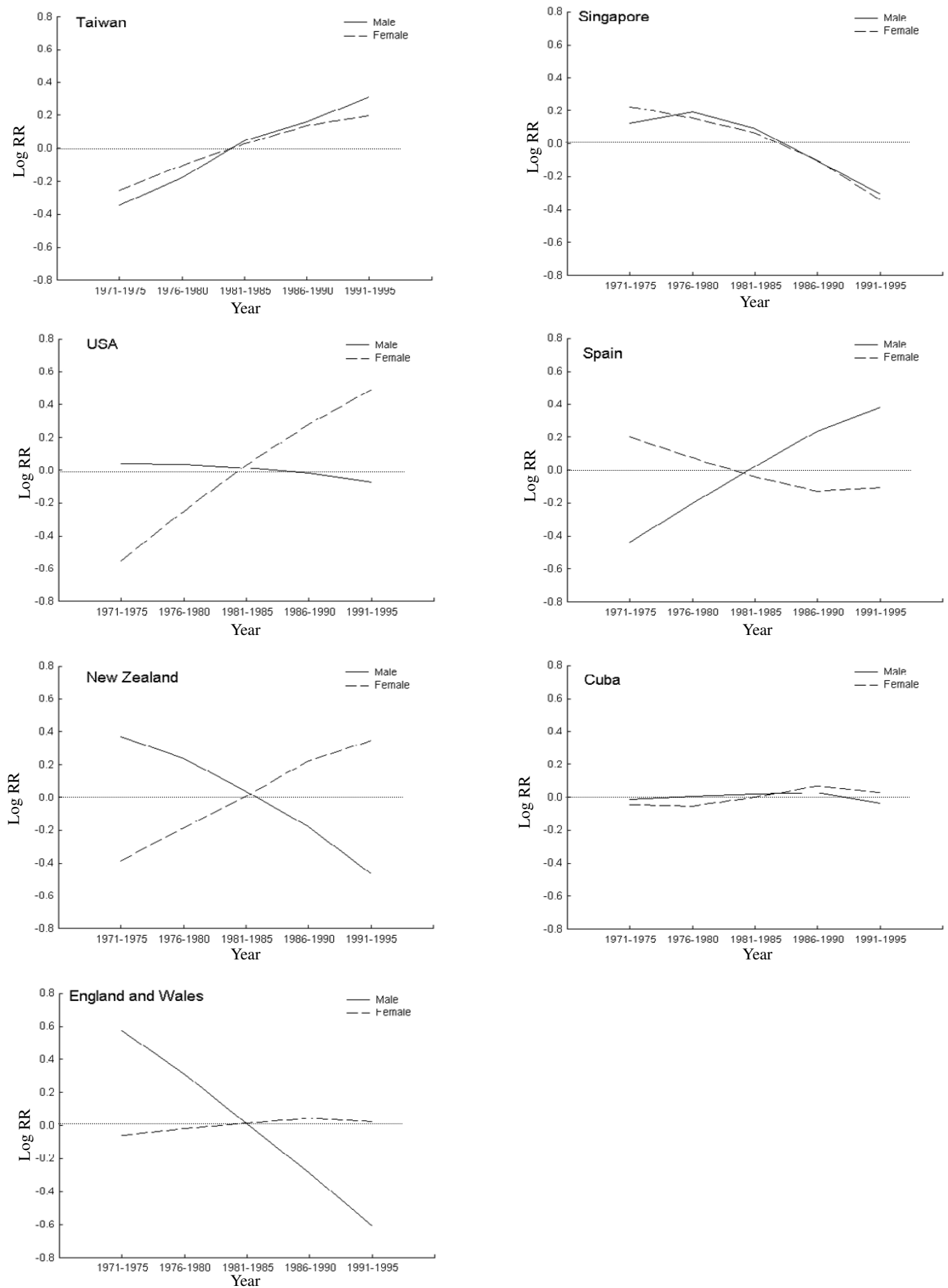

\section{Figure I}

Secular trend in the relative risk (RR) of dying from male and female lung cancer, 197I-1995, based on analyses using the ageperiod-cohort model in Taiwan, England and Wales, New Zealand, USA, Singapore, Spain and Cuba 
trend in both sexes, seen in Taiwan (Figure 1), Norway, Japan, Hungary, and Portugal; 2) a sharply increasing trend in women, with little change seen in men seen in USA (Figure 1), Sweden, Poland, Italy, Canada, Belgium, Denmark and France; 3) a sharply increasing trend in women, and a sharply decreasing trend in men, seen in New Zealand (Figure 1), Finland, Australia and Netherlands; 4) a more gradual increasing trend in women, but a sharply declining trend in men, seen only in England and Wales (Figure 1); 5) a decreasing trend in both sexes, seen in Singapore (Figure 1) and Hong Kong; 6) a decreasing and then a gradually increasing trend in women, but a sharply increasing trend in men, seen in Spain (Figure 1) and Greece; and 7) a relatively steady trend in both sexes, seen only in Cuba (Figure 1). In most countries, the longterm trend in the period effect as derived from the APC model was similar to the trend of ASMR. It is worth noting that the trend in the ASMR for female lung cancer increased and then declined in Singapore and Hong Kong. After adjusting for the cohort effect, however, a decreasing trend in the period effect was observed in Singapore and Hong Kong.

\section{Discussion}

We found that the sex ratio in lung cancer mortality varied over time and geographically. After adjusting for age and cohort effects, seven patterns could be identified using the APC model, indicating that some countries had a similar trend in lung cancer mortality.

Koo and Ho [17] indicated that smoking was a strong risk factor in the west and worldwide where there were high rates of smoking in men. We appreciate that lung cancer mortality rates for a given year depend on smoking habits over a period before that year; however, it is not possible to get data on smoking prevalence before 1975 from WHO. Therefore, based on the smoking prevalence obtained from World Health Organization (Table 4), the first, second, third, and fifth highest sex ratios (male:female) of smoking prevalence among the 23 countries were in Taiwan, Hong Kong, Singapore, and Japan, respectively. However, the sex ratios of ASMR from lung cancer in the four Asian countries were significantly lower than in the western countries. That is, the four Asian countries have a relatively low sex ratio in lung cancer mortality and a relatively high sex ratio in smoking prevalence. This fact is of particular interest.

Table 4: Smoking prevalence in males and females, and their sex ratio, in 23 countries

\begin{tabular}{|c|c|c|c|c|c|}
\hline \multirow[t]{2}{*}{ Country } & \multicolumn{5}{|c|}{ Prevalence } \\
\hline & Male & Female & Male: female ratio & Rank* & Data source $\$$ \\
\hline Taiwan & 55.1 & 3.3 & 16.7 & 1 & Adult (18 years \& older), 1996 \\
\hline Hong Kong & 27.1 & 2.9 & 9.3 & 2 & Adult ( 15 years \& older), 1998 \\
\hline Singapore & 26.9 & 3.1 & 8.7 & 3 & Adult (18-64 year olds), 1998 \\
\hline Portugal & 30.2 & 7.1 & 4.3 & 4 & Adult ( 15 years \& older), 1995-1996 \\
\hline Japan & 52.8 & 13.4 & 3.9 & 5 & Adult ( 15 years \& older), 1998 \\
\hline Poland & 39.0 & 19.0 & 2.1 & 6 & Adult, 1998 \\
\hline Italy & 32.2 & 17.3 & 1.9 & 7 & Adult (14 years \& older), 1998 \\
\hline Cuba & 48.0 & 26.3 & 1.8 & 8 & Adult ( 15 years \& older), 1995 \\
\hline Spain & 42.1 & 24.7 & 1.7 & 9 & Adult ( 16 years \& older), 1997 \\
\hline Greece & 46.0 & 28.0 & 1.6 & 10 & Adult, $1994-1998$ \\
\hline Hungary & 44.0 & 27.0 & 1.6 & 11 & Adult (18 years \& older), 1998-1999 \\
\hline France & 39.0 & 27.0 & 1.4 & 12 & Adult (18 years \& older), 1997 \\
\hline Finland & 27.0 & 20.0 & 1.4 & 13 & Adult (15-64 year olds), 1999 \\
\hline USA & 27.6 & 22.1 & 1.3 & 14 & Adult (18 years \& older), 1997 \\
\hline Netherlands & 37.0 & 30.0 & 1.2 & 15 & Adult ( 15 years \& older), 1998 \\
\hline Belgium & 31.0 & 26.0 & 1.2 & 16 & Adult (15 years \& older), 1999 \\
\hline Canada & 27.0 & 23.0 & 1.2 & 17 & Adult ( 15 years \& older), 1999 \\
\hline Australia & 27.1 & 23.2 & 1.2 & 18 & Adult ( 16 years \& older), 1995 \\
\hline New Zealand & 26.0 & 24.0 & I.I & 19 & Adult ( 15 years \& older), 1998 \\
\hline Denmark & 32.0 & 30.0 & I.I & 20 & Adult (14 years \& older), 1998 \\
\hline England and Wales & 29.0 & 28.0 & 1.0 & 21 & Adult ( 16 years \& older), 1996 \\
\hline Norway & 33.7 & 32.3 & 1.0 & 22 & Adult (16-74 year olds), 1998 \\
\hline Sweden & 17.1 & 22.3 & 0.8 & 23 & Adult (16-84 year olds), 1998 \\
\hline
\end{tabular}

*Rank by Male: female ratio

\$Data were obtained from the World Health Organization 
Table 5: Changes in annual per caput fat consumption in 23 countries

\begin{tabular}{|c|c|c|c|c|}
\hline \multirow[b]{2}{*}{ Country } & \multicolumn{4}{|c|}{ Fat Consumption* } \\
\hline & 1970 & 1990 & Percent increase & Rank $^{\&}$ \\
\hline Taiwan & 38.0 & 136.8 & $260.0 \%$ & I \\
\hline Hong Kong & $71.4 \$$ & $135.6 \#$ & $89.9 \%$ & 2 \\
\hline Spain & 88.9 & 137.0 & $54.1 \%$ & 3 \\
\hline Portugal & 78.6 & 120.6 & $53.4 \%$ & 4 \\
\hline Japan & 54.6 & 79.3 & $45.2 \%$ & 5 \\
\hline Greece & 101.9 & 138.4 & $35.8 \%$ & 6 \\
\hline Hungary & 115.3 & 153.5 & $33.1 \%$ & 7 \\
\hline Italy & 114.4 & 151.0 & $32.0 \%$ & 8 \\
\hline France & 126.4 & 161.3 & $27.7 \%$ & 9 \\
\hline Cuba & 67.6 & 85.1 & $25.9 \%$ & 10 \\
\hline New Zealand & 115.4 & 134.7 & $16.7 \%$ & 11 \\
\hline USA & 119.6 & 138.8 & $16.1 \%$ & 12 \\
\hline Canada & 113.7 & 127.1 & $11.8 \%$ & 13 \\
\hline Australia & 117.8 & 130.6 & $10.9 \%$ & 14 \\
\hline Netherlands & 132.0 & 140.9 & $6.7 \%$ & 15 \\
\hline Poland & 103.9 & 110.3 & $6.2 \%$ & 16 \\
\hline Sweden & 116.8 & 122.6 & $5.0 \%$ & 17 \\
\hline Finland & 123.6 & 124.2 & $0.5 \%$ & 18 \\
\hline Norway & 131.6 & 127.7 & $-3.0 \%$ & 19 \\
\hline England \& Wales & 141.7 & 135.8 & $-4.2 \%$ & 20 \\
\hline Denmark & 140.7 & 132.6 & $-5.8 \%$ & 21 \\
\hline Belgium & - & - & - & - \\
\hline Singapore & - & - & - & - \\
\hline
\end{tabular}

*Data were obtained from FAO

\&Rank by percent increase

\$:1961,\#: 1995

Dietary fat consumption has been found to be positively related to lung cancer mortality [18-20]. Our data from Japan, Taiwan and Cuba women (on Tables 2 and 5) also indicated that the percent increase of fat consumption was positively related to the percent increase of ASMR by using the Spearman's rank correlation coefficient. Further study of factors other than smoking, like fat intake, on lung cancer mortality seems warranted, especially for women in Asian countries (Japan and Taiwan).

\section{Conclusion}

Period effects for both men and women in 23 countries, as derived using the APC model, could be classified into seven patterns. The four Asian countries have a relatively low sex ratio in lung cancer mortality and a relatively high sex ratio in smoking prevalence. Factors other than smoking might be important, especially for women in Asian countries.

\section{Competing interests}

The author(s) declare that they have no competing interests.

\section{Authors' contributions}

YPL was responsible for the development of intellectual content and the study design, collected and analyzed the data, interpretation of the results, manuscript drafting and the critical revisions of manuscript. YCH was responsible for the development of intellectual content, interpretation of the results and manuscript drafting. GWL was responsible for data coding and entry and statistical analyses.

\section{Acknowledgements}

This study is funded by the National Science Council grant NSC 92-2320B-040-050. The authors thank Dr. Wen-Chung Lee for providing the program of the APC model.

\section{References}

I. World Cancer Research Fund / American Institute for Cancer Research: Food, nutrition and the prevention of cancer: a global perspective. Washington (DC): American Institute for Cancer Research; 1997:37.

2. Travis WD, Travis LB, Devesa SS: Lung cancer. Cancer 1995, 75(suppl I): $191-202$.

3. American Cancer Society: Cancer facts and figures - 1994. Atlanta (GA): American Cancer Society; 1994:I-28.

4. López-Abente G, Pollán M, de la Iglesia P, Ruiz M: Characterization of the lung cancer epidemic in the European Union (19701990). Cancer Epidemiol, Biomarkers \& Prev 1995, 4:8I 3-20. 
5. Department of Health: Vital Statistics, 197/-200I. Taipei, Department of Health 2002.

6. Waldron I: The contribution of smoking to sex differences in mortality. Publ Hlth Rep 1986, I 0 I: 163-73.

7. Shopland DR: Tobacco use and its contribution to early cancer mortality with a special emphasis on cigarette smoking. Environ Health Perspect 1995, 103(suppl 8): 13|-42.

8. Shopland DR, Eyre HJ, Pechacek TF: Smoking-attributable cancer mortality in 1991: is lung cancer now the leading cause of death among smokers in the United States? J Natl Cancer Inst | 99|, 83:| | $42-8$.

9. Koo LC, Ho JH, Lee $\mathrm{N}$ : An analysis of some risk factors for lung cancer in Hong Kong. Int J Cancer 1985, 35:49-55.

10. MacLennan R, Da Costa J, Day NE, Law CH, Ng YK, Shanmugaratnam K: Risk factors for lung cancer in Singapore Chinese, a population with high female incidence rates. Int J Cancer 1977, 20:854-60

II. Gao YT, Blot W], Zheng W, Ershow AG, Hsu CW, Levin LI, Zhang R, Fraumeni JF Jr: Lung cancer among Chinese women. Int J Cancer 1987, 40:604-9.

12. Chen CJ, Wu HY, Chuang YC, Chang AS, Luh KT, Chao HH, Chen KY, Chen SG, Lai GM, Huang HH, Lee HH: Epidemiologic characteristics and multiple risk factors of lung cancer in Taiwan. Anticancer Res 1990, 10:97।-6.

13. Ko YC, Lee CH, Chen MJ, Huang CC, Chang WY, Lin HJ, Wang HZ, Chang PY: Risk factors for primary lung cancer among nonsmoking women in Taiwan. Int J Epidemiol 1997, 26:24-31.

14. Waterhouse JAH, Muir C, Correa P, Powell J, eds: Cancer incidence in five continents. IARC Scientific Publications, No. 15, Lyon, IARC 1976, 3:.

15. Osmond C, Gardner MJ: Age, period and cohort models applied to cancer mortality rates. Stat Med 1982, I:245-59.

16. SAS Institute Inc: SAS/IML; user's guide, release 6.04 edition. Cary, NC: SAS Institute Inc 1988.

17. Koo LC, Ho JH: Worldwide epidemiological patterns of lung cancer in nonsmokers. Int I Epidemio 1990, I 9(suppl I): I4-23.

18. Wynder EL, Hebert JR, Kabat GC: Association of dietary fat and lung cancer. J Natl Cancer Inst 1987, 79:63 I-7.

19. Taioli E, Nicolosi A, Wynder EL: Possible role of diet as a host factor in the aetiology of tobacco-induced lung cancer: an ecological study in southern and northern Italy. Int J Epidemiol |99|, 20:6| |-4.

20. Jain M, Burch JD, Howe GR, Risch HA, Miller AB: Dietary factors and risk of lung cancer: results from a case-control study, Toronto, 198I-1985. Int J Cancer 1990, 45:287-93.

\section{Pre-publication history}

The pre-publication history for this paper can be accessed here:

http://www.biomedcentral.com/1471-2458/5/22/prepub
Publish with Biomed Central and every scientist can read your work free of charge

"BioMed Central will be the most significant development for disseminating the results of biomedical research in our lifetime. "

Sir Paul Nurse, Cancer Research UK

Your research papers will be:

- available free of charge to the entire biomedical community

- peer reviewed and published immediately upon acceptance

- cited in PubMed and archived on PubMed Central

- yours - you keep the copyright
BioMedcentral 